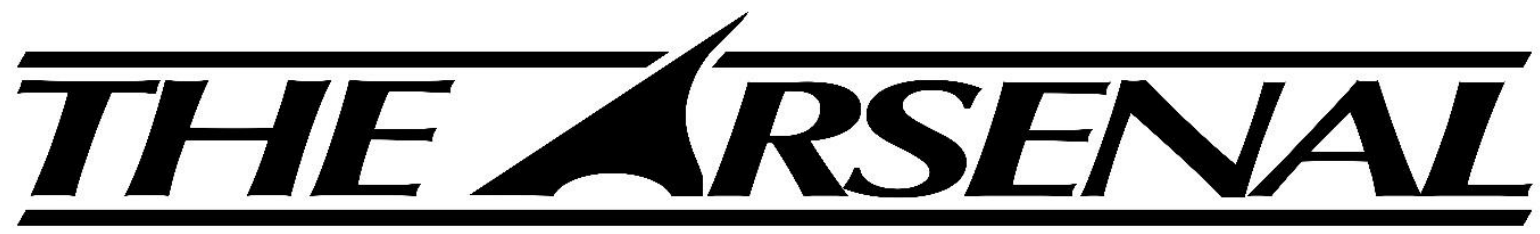

Augusta University's Undergraduate Research Journal

ISSN 2380-5064 | The Arsenal is published by the Augusta University Libraries | http://guides.augusta.edu/arsenal

Volume 4, Issue 1 (2021)

Special Edition Issue

\title{
THE EFFECT OF SELECTIVE DELETION OF LEPTIN RECEPTOR IN ENDOTHELIAL CELLS ON HIGH-FAT-DIET- INDUCED VASCULAR ENDOTHELIAL FUNCTION
}

Vinay Mehta, Reem T. Atawia, and Eric J. Belin de Chantemèle

\section{Citation}

Mehta, V., Atawia, R., \& Belin de Chantemèle, E. J. (2021). The effect of selective deletion of leptin receptor in endothelial cells on high-fat-diet-induced vascular endothelial function. The Arsenal: The Undergraduate Research Journal of Augusta University, 4(1), 25. http://doi.org/10.21633/issn.2380.5064/s.2021.04.01.25

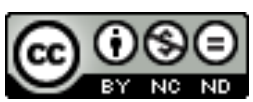

(C) Mehta et al. 2021. This open access article is distributed under a Creative Commons Attribution NonCommercial-NoDerivs 2.0 Generic License (https://creativecommons.org/licenses/by-nc-nd/2.0/). 


\title{
The Effect of Selective Deletion of Leptin Receptor in Endothelial Cells on High-Fat-Diet- Induced Vascular Endothelial Function
}

Presenter(s): Vinay Mehta

Author(s): Vinay Mehta, Reem T. Atawia, and Eric J. Belin de Chantemèle

Faculty Sponsor(s): Eric J. Belin de Chantemèle, $\mathrm{PhD}$

Affiliation(s): Vascular Biology Center (Augusta Univ.)

Funding: National Heart, Lung, and Blood Institute

\begin{abstract}
This project aimed to investigate the consequences of the selective deletion of the leptin receptor from vascular endothelial cells on vascular function in a mouse model of obesity. Obesity was induced by feeding wild-type (WT) and leptin receptor-knockout mice (ECKO) a high-fat diet for 12 weeks. We monitored body weight throughout the duration of the protocol and performed a glucose-tolerance test (GTT). Both WT and ECKO mice gained weight at similar rates, and both WT and ECKO mice had similar responses in the GTT. At the end of the study, the mice were sacrificed, and tissue weights, vascular function and gene expression were assessed. Quantification of the aortic expression of PFKFB3, an enzyme regulating glycolysis within endothelial cells, showed reduced levels in obese ECKO mice compared to WT. Vascular relaxation seemed to be impaired in the ECKO mice versus WT, but not to a statistically significant degree. In obese ECKO mice, vascular function was significantly recovered with 3PO, an inhibitor of PFKFB3; however, in normal-weight ECKO mice, 3PO did not reduce vascular dysfunction. Our data suggests a crucial role of the endothelial leptin receptor and the glycolytic pathway in regulating vascular endothelial function under obese conditions.
\end{abstract}

Received: 02/15/2021 Accepted: 03/30/2021

Correspondence: Vinay Mehta, Augusta University, $112015^{\text {th }}$ St. Augusta, GA 30912, vmehta@augusta.edu 